\title{
A política pública de expansão para a educação superior entre 1995 e 2010 uma abordagem neoinstitucionalista histórica
}

CRISTINA HELENA ALMEIDA DE CARVALHO Universidade de Brasília, Brasília, DF, Brasill

\section{RESUMO}

O objetivo do artigo é compreender a relação complexa da política pública para a educação superior por meio da vertente histórica do neoinstitucionalismo. As instituições são centrais no estudo da política, não apenas pela importância do Estado como ator e autor de ações específicas, mas por sua capacidade de interferir na cultura política, na estratégia dos atores e na produção da agenda de pesquisa neoinstitucionalista histórica. Por meio da análise tridimensional da política (polity, politics e policy), a pesquisa procura analisar de maneira comparativa a constituição da agenda pública, a formulação e a implementação da política educacional nos governos de Fernando Henrique Cardoso e Luiz Inácio Lula da Silva. O fio condutor é a dinâmica da Arena Decisória de Educação Superior, na qual a política pública gestada pelo Ministério da Educação (MEC) influenciou e foi influenciada pelo conjunto de atores governamentais e sociais.

PALAVRAS-CHAVE

educação superior; política pública; neoinstitucionalismo histórico. 


\section{THE PUBLIC POLICY OF HIGHER EDUCATION EXPANSION BETWEEN 1995 AND 2010: AN HISTORICAL NEO INSTITUTIONALISM APPROACH}

\section{ABSTRACT}

The aim of this paper is to understand the complex relationship of public policy for higher education, through the historical aspect of the neo institutionalism. Institutions are central to the study of politics, not only because of the importance of the state as an actor and author of specific actions, but by their ability to interfere in the political culture, the actors' strategy and on the research agenda of historical neo institutionalism. Through dimensional analysis of the policy (polity, politics and policy), the research seeks to analyze in a comparative way the constitution of the public agenda, the formulation and implementation of educational policy in the governments of Fernando Henrique Cardoso and Luiz Inácio Lula da Silva. The common thread is the dynamic of Arena Decision of Higher Education, in which public policy fomented by the Ministry of Education (MEC) has influenced and been influenced by all the governmental and social actors.

KEYWORDS

higher education; public policy; neo institutionalism history.

\section{LA POLÍTICA PÚBLICA PARA LA EXPANSIÓN DE LA EDUCACIÓN SUPERIOR ENTRE 1995 Y 2010: UN ENFOQUE HISTÓRICO NEOINSTITUCIONALISTA}

\section{RESUMEN}

El propósito de este trabajo es entender la compleja relación de la política pública de educación superior, por medio del neoinstitucionalismo histórico. Las instituciones son fundamentales para el estudio de la política, no solo por la importancia del Estado como actor y autor de acciones específicas, sino por su capacidad de interferir en la cultura política, en la estrategia de los actores y en la producción de la agenda de la investigación neoinstitucionalista histórica. A través del análisis tridimensional de la política (polity, politics y policy), la investigación trata de analizar de manera comparativa la constitución de la agenda pública, la formulación e implementación de la política educacional en los gobiernos de Fernando Henrique Cardoso y Luiz Inácio Lula da Silva. El hilo conductor es la dinámica de la Arena Decisoria de la Educación Superior, en la que la política pública fomentada por el Ministerio de Educación de Brasil (MEC) ha influido y ha sido influido por el conjunto de actores gubernamentales y sociales.

\section{PALABRAS CLAVE}

educación superior; política pública; neoinstitucionalismo histórico. 


\section{INTRODUÇÃO}

O ponto de partida da análise consiste na escolha de certo olhar a respeito da relação entre Estado e sociedade. Diversas perspectivas teóricas em ciência política debruçam-se sobre tal vínculo, mas, para fins deste trabalho, pretende-se concentrar em alguns pontos centrais da agenda de pesquisa neoinstitucionalista histórica. ${ }^{1}$ Este não se desenvolveu como um arcabouço teórico unitário, mas tornou-se ponto de encontro de estudiosos de diversas correntes nas ciências sociais, cujo princípio fundamental baseia-se na constatação de que as instituições importam e devem ser centrais para análises dos processos políticos e sociais. Não há grandes postulados e teorias gerais, mas um ferramental analítico baseado em afirmações provisórias a serem testadas e alteradas a com base nos resultados de estudos históricos. Por isso, o objetivo é apropriar-se de seu quadro metodológico aplicado à análise de políticas públicas, a fim de construir uma interpretação da política educacional direcionada à educação superior.

Baseado nas categorias de análise da vertente histórica do neoinstitucionalismo, o fio condutor da pesquisa é entender os atores e as instituições políticas (polity) como essenciais para a compreensão do processo político (politics), bem como para o desenho e a conformação das políticas públicas (policies). ${ }^{2} \mathrm{~A}$ participação de indivíduos, de grupos, de classes e do Estado no processo político, o modo pelo qual eles interpretam (ideias) e perseguem seus interesses e os resultados de seus esforços são moldados pelo arcabouço institucional, assim como a trajetória do fazer político (politics) molda e, simultaneamente, é moldada pela dimensão material da política (policy). Por um lado, o estudo da política educacional considera o elemento

1 De acordo com Hall e Taylor (2003) e Immergut (1998), a partir dos anos 1980 desenvolveram-se três vertentes: escolha racional, sociológica e histórica. Os primeiros autores distinguiram (2003) tais correntes baseados nas respostas a duas questões: Como construir a relação entre instituição e comportamento? Como explicar o processo pelo qual as instituições surgem ou se modificam?. A primeira corrente origina-se da teoria da escolha racional e da economia neoclássica e inspira-se na nova economia das instituições, na qual tem como suposto a importância dos direitos de propriedade, das rendas e dos custos de transação para o desenvolvimento e o funcionamento das instituições. Sobre a segunda corrente, cujo foco encontra-se na sociologia baseada na teoria das organizações, ver o clássico trabalho de Powell e DiMaggio (1991). Quanto à terceira vertente, consultar o compêndio organizado por Evans, Rueschemeyer e Skocpol (1985), que estabeleceu as principais características diferenciais das demais correntes.

2 A polity refere-se à dimensão institucional que se caracteriza pela ordem do sistema político, pelo sistema jurídico e a estrutura institucional do sistema político-administrativo. Em outras palavras, no âmbito do arcabouço estrutural brasileiro, a polity está representada pela constituição republicana dos três poderes, pelo federalismo e pelo sistema eleitoral. A politics é a dimensão processual, em outras palavras, o processo político, cujo caráter é dinâmico e marcado pelo conflito quanto aos objetivos, conteúdos e decisões. A policy corresponde à dimensão material, ou seja, os conteúdos concretos, tais como a configuração dos programas políticos, os problemas técnicos e o conteúdo material das decisões políticas. No lugar de três dimensões estanques, a literatura tem avançado à medida que novos estudos passaram a estabelecer relação simbiótica e de mútua influência entre essas categorias analíticas (Frey, 2000). 
inercial dado pela continuidade das políticas atribuído ao processo de realimentação promovido pelo path dependence, por outro lado, ocupa-se em identificar os traços de ruptura provenientes da mudança institucional.

Para a realização deste trabalho, o procedimento metodológico adotado foi a pesquisa documental. As fontes primárias consultadas foram: a) programas de governo e a legislação sobre o tema; b) relatórios, estudos publicados, pareceres, manifestações públicas, matérias veiculadas aos meios de comunicação e conteúdo de seminários. ${ }^{3}$

$\mathrm{O}$ artigo divide-se em três partes, além de introdução e conclusão. Na primeira seção, o texto apresenta o arcabouço teórico do neoinstitucionalismo histórico, as categorias e os conceitos que foram apropriados para análise da política pública para educação superior. Na segunda seção, procura-se delimitar a arena decisória, os atores relevantes e a agenda governamental nesse nível educacional. Na última seção, a intenção é comparar a formulação e a implementação da expansão da educação superior nos governos FHC e Lula, a fim de analisar os elementos de continuidade e/ou ruptura da política pública.

\section{NEOINSTITUCIONALISMO HISTÓRICO: CONCEITOS E CATEGORIAS}

A corrente denominada neoinstitucionalista histórica teve seus primórdios nos anos 1980, inspirada no trabalho clássico de Polanyi (1980) sobre o surgimento e o desaparecimento da sociedade de mercado. $\mathrm{O}$ arcabouço teórico apareceu como reação às análises de grupos estrutural-funcionalistas - cujo foco concentrava-se nos indivíduos e na sociedade - para resgatar o papel do Estado nas políticas públicas.

Nessa linha interpretativa, destaca-se a pesquisa de Skocpol (1985), cujo cerne consiste em colocar o Estado no lugar central para a compreensão do fazer político e da mudança social, e que, de certo modo, rompeu com os pressupostos deterministas sociais das correntes pluralistas, estrutural-funcionalistas e neomarxistas. No entanto, vale ressaltar que essa perspectiva não substituiu as explicações baseadas em classes ou grupos pelo determinismo estatal. Enquanto algumas teorias políticas buscam explicações baseadas em variáveis particulares - marxismo: classe; pluralismo: grupo de interesses -, os históricos procuram focalizar suas análises na combinação e na interação entre inúmeras variáveis, a fim de refletir a complexidade das situações políticas reais.

O método analítico dos institucionalistas históricos parte da estruturação de hipóteses de forma indutiva, durante a interpretação do material empírico. $\mathrm{O}$ objetivo central é realizar mediação teórica entre as análises centradas no Estado e na sociedade. Para a consecução dessa empreitada, é necessário incorporar variáveis de nível intermediário que levam em conta a variação histórica e conjuntural dos fenômenos (Marques, 1997). Sendo assim, para essa vertente, o próprio conceito de instituição torna-se bastante fluido, pois abrange tanto organizações formais

3 As referências mais detalhadas da "fala" dos atores podem ser encontradas em Carvalho (2011). 
como regras informais e procedimentos que estruturam a conduta. Em geral, esses teóricos procuram associar as instituições às organizações e às regras ou convenções editadas pelas organizações formais (Thelen; Steinmo, 1992).

As instituições são centrais no estudo da política, não apenas pela importância do Estado como ator e autor de ações específicas, mas, acima de tudo, pela capacidade de interferir na cultura política, na estratégia dos atores e na produção da própria agenda de questões que serão objeto de políticas (policies). As instituições desempenham o duplo papel de constranger as interações sociais e alterar as preferências dos atores, uma vez que não apenas as estratégias, mas também os objetivos dos atores são moldados pelo contexto institucional. Em outras palavras, as preferências tornam-se endógenas, resultantes do contexto social e político. ${ }^{4}$

Por tal perspectiva, em contraposição a outras correntes teóricas, o Estado deixa de ser entendido como puro aparelho de regulação da sociedade, bem como instrumento de uma classe dominante, a partir do momento em que as relações com a sociedade civil não são interpretadas em mão única do tipo dominante/ dominada. O Estado é uma instituição/ator fundamental e, dessa forma, torna-se objeto de investigação sobre como este afeta os processos políticos e sociais por meio de suas políticas e de seu relacionamento com os grupos sociais. Sendo assim, para a melhor compreensão da política pública, é importante mapear as redes mais ou menos estruturadas e hierarquizadas de relações entre o Estado e a sociedade civil que configuram o acesso diferenciado ao poder.

A capacidade do Estado de fazer valer seus interesses está intrinsecamente vinculada a seu grau de autonomia em relação à sociedade, consagrado na literatura pelo conceito de "insulamento", desenvolvido por Skocpol (1985). Trata-se da capacidade dos funcionários estatais ou do aparato burocrático de formular e realizar políticas públicas de maneira mais ou menos autônoma e/ou distinta diante das pressões dos atores sociais. O grau de insulamento tem como condicionantes a estrutura organizacional da máquina pública, a estabilidade e a consolidação das agências estatais e o maior controle do Legislativo sobre o Executivo, além da estrutura de relações e laços de poder entre, de um lado, os agentes presentes em uma determinada agência e, de outro, em nível central, as outras agências e o ambiente no qual elas estão inseridas. Portanto a autonomia estatal não é uma característica

4 March e Olsen (1984) contestam o caráter exógeno de três variáveis centrais para a compreensão dos resultados políticos. São elas: a distribuição das preferências (interesses) entre os atores políticos, a distribuição de recursos (poderes) e os constrangimentos impostos pelas regras do jogo (estruturas). Com relação à primeira variável, a crítica vai na direção do reconhecimento de que as preferências políticas são moldadas pelas experiências políticas ou pelas instituições, logo o sistema político não é estritamente dependente da sociedade relativa a ele. A segunda variável é parcialmente endógena, uma vez que as instituições políticas afetam a distribuição de recursos de poder, as quais, por sua vez, afetam o poder dos atores políticos e, finalmente, por meio disso, afetam as instituições políticas. A terceira variável - materializada em constituições, leis, contratos e regras costumeiras - envolve constrangimentos que não foram desenvolvidos e impostos pelo sistema social externo, mas construídos no interior do contexto das instituições políticas. 
estrutural do Estado capitalista, o que torna necessário o desenvolvimento de estudos históricos para cada sociedade e para cada processo de formação do Estado, a fim de identificar a autonomia de cada agência estatal em sua conjuntura específica.

As ações das agências estatais podem ser parciais e fragmentadas, assim como irracionais e desarticuladas, pois o resultado e a racionalidade são contingentes. Segundo Marques (1997), a lógica da ação estatal é a busca da autorreprodução, baseada na ação coletiva dos funcionários públicos para aumentar ou reproduzir o poder e o controle das instituições estatais sobre a sociedade. Se, por um lado, a efetividade das políticas públicas propostas dependerá das estratégias dos atores dentro e fora do Estado, além do processo de formação de suas instituições, que define em grande parte a existência ou ausência de certos "instrumentos de política" para a execução das ações; por outro, o processo de produção das políticas públicas dependerá da própria capacidade do Estado, uma vez que os agentes estatais tendem, majoritariamente, a propor políticas que possam ser postas em prática.

Um ponto importante é que os Estados são examinados em relação a tipos particulares de ambientes socioeconômicos e políticos povoados por atores com recursos e interesses dados. Para análise aprofundada da implementação de determinada política, faz-se necessário examinar a organização e os interesses do Estado e especificar a organização e os interesses dos grupos socioeconômicos, e requer o entendimento a respeito do relacionamento conflituoso entre os atores governamentais e sociais. Entretanto, cabe destacar que as relações de poder são assimétricas. Em outras palavras, as instituições repartem o poder de maneira desigual entre os grupos sociais, assim como certos grupos ou interesses têm acesso desproporcional ao processo decisório.

Os condicionantes econômicos e sociais, assim como o desenho das instituições políticas, devem ser levados em conta na configuração da democracia política. Essas são arenas de disputa das forças sociais, mas também são responsáveis por procedimentos operacionais padronizados e por estruturas nas quais os interesses são definidos e defendidos. Mais que isso, as instituições são atores políticos ou decision makers. Pode-se dizer que o Estado ou outras instituições políticas fazem escolhas baseadas em alguns interesses da coletividade ou intenções, alternativas e expectativas (March; Olsen, 1984). Da mesma maneira que devem ser levados em conta os aspectos conjunturais, pois os períodos de crise podem precipitar a formulação de estratégias oficiais e de políticas propostas pelas elites e pelos administradores, as potencialidades estruturais para as ações autônomas estatais modificam-se ao longo do tempo, já que suas organizações de coerção e administração sofrem mudanças, tanto internamente como em suas relações com os grupos sociais e partes representativas do governo (Skocpol, 1985).

Vale salientar que, no entendimento dessa vertente teórica, quando as políticas públicas são instituídas, elas reestruturam, por sua vez, os processos políticos. ${ }^{5} \mathrm{~A}$ realimentação da política ocorre por meio de dois caminhos. Em primeiro lugar,

5 “Como a política cria políticas, as políticas também remodelam a política" (Skocpol, 1994, p. 58). 
em virtude dos esforços envidados pelos funcionários públicos para executar novas políticas usando novos arranjos ou aqueles já existentes, as políticas transformam-se e ampliam as capacidades do Estado. As possibilidades administrativas são alteradas e afetam as expectativas para a implementação política. Em segundo lugar, novas políticas abalam as identidades sociais, os objetivos e as capacidades dos grupos que lutam ou se aliam em torno da agenda política. Ao longo do processo político (politics), à medida que uma política (policy) é bem-sucedida, acentuam-se as capacidades estatais que podem promover seu futuro desenvolvimento, e, sobretudo, os grupos e as alianças políticas são estimulados a defender a continuidade da política e/ou sua expansão. Portanto, a permanência está associada à dependência da trajetória percorrida - path dependence -, segundo a qual as instituições são um dos principais fatores que mantêm um desenvolvimento histórico sobre um conjunto de trajetos.

Hall e Taylor (2003) fazem referência a diversos trabalhos desenvolvidos nessa linha argumentativa, desde aqueles que, a princípio, enfatizavam as "capacidades de Estado" e as "políticas herdadas" como estruturantes das decisões posteriores, até aqueles que acreditam que as políticas já adotadas são condicionantes das posteriores. A explicação reside no encorajamento das forças sociais a organizarem-se segundo certas orientações, a adotarem identidades particulares, ou a desenvolverem interesses em políticas, uma vez que o abandono destas traria risco eleitoral. Dessa maneira, a perspectiva histórica torna-se bastante atrativa na medida em que permite compreender, por meio de um nível intermediário de análise, as continuidades políticas ao longo do tempo dentro de países e variações de política entre países.

Os argumentos da dependência da trajetória percorrida e do peso das políticas herdadas são fatores explicativos para a compreensão da inércia institucional, todavia é na análise do dinamismo que reside a flexibilidade da vertente histórica, na medida em que são incorporados dois elementos: o conflito e a escolha. Se, por um lado, as instituições são produto do conflito e das escolhas, por outro, elas modelam e restringem as estratégias políticas. Ainda que o comportamento político seja uma variável independente, em situações de mudanças conjunturais ele é influenciado por instituições e políticas anteriores (Menicucci, 2005).

Dessa forma, os momentos de mudança e de escolha institucional devem ser objeto de análise, em primeiro lugar, na medida em que

conflitos a respeito das instituições expõem as relações de interesses e poder, e seus resultados não somente refletem, mas ampliam e reforçam os interesses dos vencedores, desde que as amplas trajetórias políticas possam resultar de escolhas institucionais. (Thelen; Steinmo, 1992, p. 27, tradução nossa)

Em segundo lugar, ainda que a transformação institucional possibilite moldar as ideias, atitudes e preferências, a importância reside na alteração dos constrangimentos a que são submetidos os atores em suas escolhas estratégicas, transformando os objetivos vinculados à ação política. Torna-se necessário entender a relação dinâmica entre a escolha de certas ideias (e interesses) em detrimento de outras, de modo que exerça influência no processo de elaboração das políticas e no surgimento de inovações com base em um momento peculiar. 
Além das situações de crise como fatores explicativos da mudança institucional, deve-se acrescentar o aprendizado social, os processos de transferência, imitação e difusão das políticas (mimicking), segundo os quais os formuladores de políticas observam as melhores práticas e adotam os modelos ou padrões usados no exterior. Isso ocorre mediante a influência das instituições multilaterais na definição das agendas de reformas econômicas e sociais dos países em desenvolvimento.

\section{EDUCAÇÃO SUPERIOR: ARENA DECISÓRIA, PRINCIPAIS ATORES E A FORMAÇÃO DA AGENDA}

Sendo assim, faz-se necessário para a compreensão da política pública a delimitação da arena na qual se estabelecem as relações que abrangem negociação/ compromisso, bem como disputa/conflito entre os atores relevantes. Nesta pesquisa, arquitetou-se a arena decisória virtual que se denomina "educação superior", por considerá-la mais apropriada diante da abrangência da ação estatal e de suas reações no setor educacional. Esta pode ser compreendida como arena decisória central na medida em que permite o acesso e a participação de amplo espectro de atores envolvidos da formulação até a implementação da política educacional. No que concerne à expansão, trata-se de arena classificada por Lowi (1995) como redistributiva, uma vez que a estrutura política parece ser altamente estabilizada e virtualmente institucionalizada, conformando-se complexo equilíbrio em larga escala. Essa estabilidade decorre da existência de pelo menos "dois lados" imbuídos de interesses compartilhados, estáveis, claros e consistentes baseados em ideologias. A negociação é possível somente com o propósito de fortalecimento ou enfraquecimento do impacto da redistribuição.

$\mathrm{Na}$ arena da educação superior aparecem claramente os atores defensores de interesses polarizados públicos e privados vinculados ao acesso ao nível superior. O Congresso Nacional, sobretudo a Comissão de Educação e Cultura da Câmara dos Deputados, constitui-se no lócus preferencial de concretude dessa arena decisória, onde o processo político materializa-se como campo de interação, ou seja, tornando-se espaço de debate e ação (confronto e interação).

Os atores são "todos aqueles dotados de capacidade de articular interesses, formalizar reivindicações e convertê-las em iniciativas, prescrever soluções, promover sua solução ou impedir que as decisões sejam implementadas" (Martins apud Tápia, 1993, p. 20).

Todavia, é importante considerar que nenhum ator, de forma isolada, impõe sua alternativa preferencial de política com base apenas em seus recursos de poder. Para um processo de mudança ou alternativa de política, outros interesses devem ser agregados, tendo em vista que os recursos são, em geral, escassos e diversamente distribuídos entre os atores em cada situação considerada (Silva, 1992). ${ }^{6}$

6 Sobre a diversidade de atores individuais que influenciam a política pública para educação superior, consultar Carvalho (2011). 
Para fins desta pesquisa, foram selecionados apenas grupos formais ou organizações os quais participaram ou interferiram de forma efetiva na política educacional para o nível superior. Sendo assim, classificam-se o ator governamental representado pela burocracia do Ministério da Educação (MEC) e os atores sociais defensores de interesses do segmento privado (Associação Brasileira de Mantenedores de Ensino Superior [ABMES] e Associação Brasileira das Universidades Comunitárias [ABRUC]) e federal (Associação Nacional dos Dirigentes das Instituições Federais de Ensino Superior [ANDIFES] e Sindicato Nacional dos Docentes das Instituições de Ensino Superior [ANDES-SN] e União Nacional dos Estudantes [UNE]) e daquele com interesses híbridos (Conselho de Reitores das Universidades Brasileiras - CRUB), bem como os organismos multilaterais, cujos representantes são o Banco Mundial (Banco Internacional para Reconstrução e Desenvolvimento - BIRD) e a Organização das Nações Unidas para a Educação, a Ciência e a Cultura (UNESCO). ${ }^{7}$

A composição da agenda governamental (agenda setting), como uma das etapas do ciclo político (policy cycle), é um momento central para análise da política pública. De acordo com Theodoulou (1995), uma questão tem chance de ser inserida na agenda quando serve para resolução de um conflito ou crise, quando é defendida por um grupo de interesse visível ou pelo apoio do aparato burocrático. Os eventos políticos (eleições) e a consequente nova administração estatal fluem de acordo com suas próprias dinâmicas e regras e apresentam papel significativo na formação da agenda. Por isso, os programas de governo dos candidatos vitoriosos à presidência da República em 1994, 1998 e 2002 serão utilizados como uma proxy da agenda governamental para a educação superior. Ainda que se pondere sobre a validade das propostas aventadas durante campanhas políticas, optou-se por fazer uso desses documentos, no que concerne ao sistema educacional superior, uma vez que se mostraram concatenados com a formulação da política pública e são de uso corrente pelos pesquisadores da área.

Em linhas gerais, o primeiro documento (1994), denominado "Mãos à obra", apresentou a proposta para o segmento particular que incluía três pontos: a) a reformulação do sistema de autorização de estabelecimentos e cursos, considerada restritiva e que pouco contribuía para aumentar a concorrência no setor; b) a fixação de critérios para distribuição de recursos públicos às instituições de ensino superior (IES) comunitárias; e c) a reestruturação do crédito educativo. $\mathrm{O}$ documento sugeria ao segmento federal uma revolução administrativa vinculada à autonomia nas universidades, a fim de racionalizar os recursos orçamentários, por meio de três medidas: a) utilizar a capacidade ociosa; b) generalizar os cursos noturnos; e c) aumentar as matrículas, sem despesas adicionais. Tal expansão deveria ocorrer por meio de parceiras com os entes da federação ou as comunidades locais.

Em 1998, o candidato à reeleição lançou novo programa de governo intitulado "Avança Brasil", com um diagnóstico mais detalhado dos problemas que se perenizaram na educação superior, tais como a pequena proporção de jovens

7 Ver mais informações sobre esses atores sociais em Carvalho (2011). 
matriculados no sistema e a rigidez dos modelos institucionais. No comando da pasta da Educação, permanecia Paulo Renato Souza, logo, a diferença entre os dois programas residia em mudança na forma, sendo que o primeiro apresentou objetivos gerais e o segundo passou a definir metas quantitativas. Para o conjunto do sistema, pretendia-se ampliar em 30\% as matrículas, por meio da redução das desigualdades regionais, da diversificação no acesso e na composição da oferta cursos de curta duração, sequenciais e a distância - e da flexibilidade curricular. Para o segmento privado, o foco concentrava-se na reorganização e ampliação do crédito educativo para atender $15 \%$ da clientela das IES. Para o segmento federal, pretendia-se incrementar as matrículas em $40 \%$ nos cursos de graduação nas instituições federais de ensino superior (IFES), instituir a autonomia universitária em termos administrativos e financeiros e promover a melhoria da qualificação do corpo docente associada a sua avaliação.

Por sua vez, o programa de governo do candidato vitorioso à presidência da República em 2002, Luiz Inácio Lula da Silva, pode ser encontrado em dois documentos. No primeiro, intitulado "Um Brasil para todos", fez-se dura crítica ao governo anterior quanto à insuficiência do investimento na educação, e a ênfase residia na necessidade de recuperar a rede pública, em todos os níveis, inclusive as universidades, valorizando principalmente a qualidade. Reprovavam-se as características da política educacional da gestão precedente: a descentralização executiva, o controle centralizado, a privatização do atendimento e a insuficiência global de recursos.

Quanto ao avanço do processo de privatização, o documento afirmou que esse fenômeno ocorria em virtude do acelerado aumento proporcional da rede privada, a cada dia com maior peso no sistema superior. Ainda assim, identificou-se, por meio de dados do Censo da Educação Superior de 2000, a insuperável dificuldade das camadas mais pobres em acessar esse nível educacional. Mesmo quando essa barreira é transposta, persiste o desafio da permanência do aluno mediante os elevados gastos com as mensalidades nos estabelecimentos privados. Os gargalos para o segmento particular são as elevadas taxas de inadimplência e evasão, associadas ao sistema de crédito educativo insuficiente e inadequado. A agenda governamental incluía como tarefas futuras, de modo que contemplasse os dois segmentos, a ampliação significativa das vagas nas universidades públicas e a reformulação do sistema de crédito educativo vigente. Ademais, havia a preocupação com todos os elos educacionais, da creche à pós-graduação, e, portanto, deveriam contar com recursos progressivamente maiores.

O segundo documento representativo da agenda governamental, chamado "Uma escola do tamanho do Brasil", foi confeccionado, no mesmo ano, pelo Grupo de Trabalho "Educação, Ciência e Tecnologia", do Partido dos Trabalhadores (PT), cujo teor específico sobre o setor educacional proporcionou análise mais aprofundada que aquela contida no programa de governo. Havia duas seções exclusivas sobre educação superior. A primeira expunha o diagnóstico, e a segunda exibia as propostas e as metas. Nos pressupostos gerais e nas diretrizes, a educação superior foi reconhecida não apenas por sua funcionalidade consensual - na formação acadêmica e ética de recursos humanos, nas atividades de pesquisa científica e tecnológica e 
no desenvolvimento cultural, econômico e social -, mas também como um direito social básico diante de sua intensa demanda pelas camadas populares. Percebe-se mudança na estratégia discursiva entre os dois governos analisados. Enquanto a proposta do candidato Fernando Henrique Cardoso atribuía a crise da educação superior às universidades federais e mostrava-se defensora da livre iniciativa nesse nível educacional, corroborando com as recomendações do BIRD - que concebia a educação superior como um serviço comercializado no mercado -, a proposta do candidato Lula fez questão de criticar a privatização exacerbada do sistema educacional associada à constatação de que as IFES foram desamparadas e viviam em situação de penúria em razão da queda no aporte de verbas federais. A crítica foi dirigida à gestão precedente quando afirmou que o investimento estatal mais substancial no setor era considerado desperdício de dinheiro público.

Tendo em vista o limite do artigo acadêmico, optou-se por abordar um dos eixos estruturantes da política educacional - expansão da educação superior - para comparar a formulação e a colocação em prática da política educacional entre os governos FHC e Lula, de modo que se analisassem os elementos de continuidade e/ou ruptura da política pública. ${ }^{8}$

\section{A POLÍTICA PÚBLICA PARA A EXPANSÃO DA EDUCAÇÃO SUPERIOR NO BRASIL ENTRE 1995 E 2010}

A agenda governamental delineada nos programas de governo de FHC (1995-2002) foi, aos poucos, sendo traduzida na legislação promulgada da Lei de Diretrizes e Bases da Educação Brasileira (LDB) (lei n. 9.394/1996) e do Plano Nacional de Educação (lei n. 10.172/2001) para o período de 2001 a 2010, além das demais normas jurídicas avulsas. Ao longo dos oito anos do mandato presidencial, o conjunto de intenções em seus planos de governo foram traduzidos de modo coerente na formulação e na implementação da política educacional. No Governo Lula (2003-2010), a reforma da educação superior não saiu do papel, entretanto houve uma profusão de leis, decretos e portarias sobre o assunto, com destaque para o Programa Universidade para Todos (ProUni) a partir de 2005 (lei n. 11.096/2005) e o Programa de Apoio a Planos de Reestruturação e Expansão das Universidades Federais (REUNI) a partir de 2008 (decreto n. 6.096/2007).

É possível desmembrar a agenda governamental de expansão focada em benefício da oferta em quatro premissas, que favoreceram sobretudo o segmento particular: a) diversificação de cursos; b) diferenciação institucional; c) combate às desigualdades regionais em termos educacionais; d) expansão via cursos noturnos. A agenda estatal também se dirigiu à demanda estudantil, cujo estímulo restringiu-se a dois mecanismos: a) criação de novas formas de acesso; b) constituição de políticas afirmativas.

8 Sobre os demais eixos estruturantes da política para educação superior, ver Carvalho (2011). 
Na sequência do texto, cada elemento será discutido levando-se em conta as visões dos atores sociais, bem como será explicitado o posicionamento do MEC, traduzido em medidas legais e concretas, e em seguida serão mapeadas as respostas desses atores de aprovação e/ou desaprovação mediante as mudanças efetuadas.

Objeto de grande controvérsia entre os atores sociais, a diversificação na oferta de cursos e programas polarizou a discussão. A ABMES, ${ }^{9}$ a ABRUC $^{10}$ e o CRUB, ${ }^{11}$ assim como o Banco Mundia ${ }^{12}$ e a UNESCO, ${ }^{13}$ são favoráveis a tal medida, sob o argumento de promover a democratização do acesso. Segundo eles, a vantagem reside na flexibilidade institucional, uma vez que as IES apresentam adaptação rápida a mutações na procura, relacionadas ao aumento ou à queda de diferentes áreas de estudo, assim como às mudanças na composição das aptidões novas profissões nos níveis tecnológicos e administrativos - procuradas pelo mercado de trabalho. Essa posição é reforçada pela visão dos dois organismos multilaterais, que reconhecem a tendência positiva à diferenciação institucional na educação superior - caracterizada pela constituição de programas de estudos breves e de sistemas de ensino a distância -, cujos fatores explicativos residem nas necessidades recentes do mercado de trabalho e na diversidade do público estudantil.

Por sua vez, o ANDES-SN, ${ }^{14}$ a $\mathrm{UNE}^{15}$ e a ANDIFES ${ }^{16}$ assumiram um posicionamento bastante crítico à criação de cursos não tradicionais, porque os consideravam invariavelmente de baixa qualidade. A exceção fica por conta da ANDIFES, que defende a modalidade não presencial e cujo argumento baseia-se na necessidade de alcançar uma clientela que está fora do sistema educacional e tem dificuldades de frequentar um curso presencial, como a formação de professores em exercício, aqueles trabalhadores que exercem suas atividades em regime de turno, os presidiários e as pessoas com grandes limitações de locomoção.

9 O posicionamento da ABMES a respeito dos instrumentos que viabilizariam a expansão na educação superior foi retirado do seminário realizado pela entidade (ABMES, 1997a), bem como de documentos institucionais (1997b, 1999a, 1999b, 2004).

10 O posicionamento da ABRUC pode ser captado pelo artigo de Bittar (2001), no qual a autora entrevistou um dos presidentes da entidade, e no periódico de sua publicação, Comunitárias, que se encontra disponível no site www.abruc.org.br. Ver também: “Comunitárias..." (2004), cujo conteúdo aborda a visão de outro presidente da entidade sobre o ProUni.

11 A concepção do CRUB foi analisada pelas seguintes publicações: CRUB $(1999,2006)$.

12 O pensamento do Banco Mundial ora analisado foi retirado dos seguintes textos publicados pelo banco: World Bank (1995, 2000, 2003).

13 A visão da UNESCO foi retida por meio dos seguintes documentos: UNESCO (1995, 1998, 2003); Delors (1996).

14 Os documentos que refletem o pensamento do ANDES-SN foram os seguintes: ANDES-SN (1989a, 1989b, 1991, 2003, 2004a, 2004b, 2005, 2007).

15 A visão da UNE foi observada por meio dos seguintes textos: UNE (2004, 2005a, 2005b).

16 O pensamento da ANDIFES foi analisado com base nos seguintes documentos: ANDIFES (1996, 2004a). Sobre a crítica da entidade ao ProUni, é importante observar a deliberação do Conselho Pleno da ANDIFES, na reunião realizada em 18/3/2004 (ANDIFES, 2004b). O secretário executivo da ANDIFES demonstra o apoio institucional ao REUNI, em Balduino (2008). 
No Governo FHC, a diversificação de cursos e de programas tornou-se questão essencial da política de expansão de vagas, contemplando os interesses dos atores vinculados aos interesses das IES privadas e as recomendações dos dois organismos multilaterais, baseando-se no mesmo argumento defendido por seus interlocutores, o qual se abria à possibilidade de acesso à vasta demanda reprimida que não poderia frequentar um curso convencional. Em outras palavras, para aumentar a escolaridade líquida, tornava-se necessário dar oportunidade educacional às camadas mais pobres e de trabalhadores em cursos não tradicionais, mais curtos e voltados, precipuamente, ao mercado de trabalho. Para atingir esse objetivo, foram formuladas e postas em prática três novas modalidades de cursos: sequencial, tecnológico e não presencial.

Por sua vez, o Governo Lula, em seu programa de governo e no documento prévio à proposta de reforma, fez questão de marcar posição contrária à diversidade da oferta conduzida pelo segmento particular, uma vez que a democratização do acesso não havia se concretizado. Essa constatação foi corroborada pelos dados empíricos, que evidenciaram a permanência de brutal desigualdade na representação dos extratos de renda e do ínfimo resultado da escolaridade líquida. No entanto, as três modalidades de cursos apresentam aspecto inercial, pois a consolidação dessas iniciativas realimentou a continuidade da ação estatal, por um lado, pelo surgimento de nichos de mercado específicos bastante rentáveis para cada instituição, e, por outro lado, pela clientela ávida em ingressar no seleto grupo de pessoas com nível superior. Qualquer tentativa de interrupção dessa trajetória certamente encontraria grande resistência de ambos.

Novo objeto de controvérsia, a diferenciação institucional teve como aliados o Banco Mundial e a ABMES, em defesa de novos fornecedores privados e de instituições não universitárias mais inovadoras, sob a alegação da necessidade de ampliar a concorrência, enquanto a UNESCO reconhece como inevitável o surgimento dessas IES e pondera, tanto quanto o BIRD, sobre a importância da regulação para manter a qualidade do ensino ofertado. O CRUB manteve-se neutro. A ABRUC fez questão de demarcar seu posicionamento em prol das IES não lucrativas submetidas ao modelo universitário, e o ANDES-SN, a UNE e a ANDIFES desaprovam a existência de um modelo empresarial, assim como instituições não universitárias, pois acreditam que tais IES serviriam apenas aos desígnios do mercado, sem qualquer preocupação com a qualidade do ensino.

A ação estatal foi conduzida em duas frentes. Quanto à dependência administrativa, regulamentou-se a figura jurídica da empresa educacional, e os critérios necessários para tipificar uma instituição educacional não lucrativa foram ampliados e mais rigorosos. No que tange à organização acadêmica, foram criados dois novos modelos: os centros universitários e os institutos superiores ou escolas superiores.

Diante da continuidade da diversificação de cursos, sobretudo sequenciais e a distância, os atores estatistas mantiveram a postura crítica com relação a esses modelos de oferta, com exceção da ANDIFES, defensora da educação a distância, enquanto os atores vinculados ao segmento privado posicionaram-se em sua defesa.

A política pública no Governo Lula, apesar das críticas de campanha à privatização exacerbada promovida por seu antecessor, mais uma vez não pôde alterar a dependência da trajetória percorrida, restando a ela conservar a legislação existente, 
quando muito, aperfeiçoá-la ou restringir sua aplicabilidade. Quanto à organização acadêmica, a política pública direcionou-se em duas frentes: estabelecer critérios mais rigorosos para a definição dos formatos de universidades e centros universitários em relação àqueles fixados por seu antecessor, com o intuito de atingir, em especial, o segmento particular e, ao mesmo tempo, realçar a importância das universidades públicas, que haviam sido preteridas e desprestigiadas no Governo FHC.

No primeiro ano de mandato, ficou evidente o intuito de o governo coibir a expansão desse modelo institucional por meio da proibição expressa de constituírem-se novos centros universitários, exceto aqueles com processo de credenciamento em trâmite ou que atendessem às necessidades sociais, segundo os critérios definidos pelo MEC. Ademais, para os existentes, o regulamento determinou a obediência aos mesmos requisitos constitutivos de uma universidade. Caso a instituição não cumprisse essa resolução, previa-se o imediato descredenciamento do centro universitário, retornando ele a sua situação anterior no MEC. Essa norma jurídica vigorou até sua revogação, no final do primeiro mandato, que restabeleceu a possibilidade de constituição desse formato institucional, assim como as prerrogativas de autonomia normatizadas pelo governo anterior, e fixou apenas dois requisitos brandos: um quinto do corpo docente em regime de tempo integral e pelo menos um terço com titulação acadêmica de mestrado ou doutorado. A tônica passou a ser de nova frouxidão regulatória para essas instituições, sob os protestos dos atores representantes da comunidade acadêmica federal e os festejos dos representantes das privadas.

Por sua vez, a ação estatal caminhou no sentido de priorizar a expansão do segmento federal, concretizada por meio da criação de novas universidades federais e da construção de novos campi nas já existentes. O Programa de Expansão Fase I, com forte caráter de interiorização das universidades, teve seu início em 2003, e o prazo para sua conclusão era 2010. Mas só é possível vislumbrar esse movimento quando a análise extrapola o período compreendido pelo primeiro mandato. A política de incremento de vagas tomou novo formato na segunda gestão de Lula sob a batuta do ministro Fernando Haddad, impulsionada pelo crescimento econômico e pela maior disponibilidade de recursos da União direcionados à recuperação das verbas de custeio, pessoal e investimentos. No bojo do Plano de Desenvolvimento da Educação (PDE), o governo federal lançou, por meio do decreto n. 6.096/2007, o REUNI.

Nesse sentido, o incremento de vagas seria realizado pela melhoria, sobretudo, de dois indicadores específicos: a elevação gradual da taxa de conclusão média dos cursos de graduação presenciais para $90 \%{ }^{17}$ e da relação de alunos de graduação em cursos presenciais por professor para dezoito, ${ }^{18}$ ao final de cinco anos. Além disso, prevê-se a redução das taxas de evasão, a ocupação de vagas ociosas e o aumento das

17 A taxa de conclusão dos cursos de graduação é calculada pela relação do total de diplomados nos cursos de graduação presenciais em determinado ano e o total de vagas de ingresso oferecidas cinco anos antes.

18 A meta de dezoito alunos de graduação por professor diz respeito à oferta esperada de vagas nos cursos de graduação presenciais em razão das dimensões do corpo docente 
vagas de ingresso, em especial no período noturno. A proposta de adesão deveria contemplar acréscimo mínimo de $20 \%$ nas matrículas de graduação.

$\mathrm{Na}$ linha da expansão com diversidade institucional, o Governo Lula deu novo rumo à educação tecnológica a partir do processo de reordenamento que instituiu a Rede Federal de Educação Profissional, Científica e Tecnológica, composta de Institutos Federais de Educação, Ciência e Tecnologia (IFET); da Universidade Tecnológica Federal do Paraná (UTFPR); do Centro Federal de Educação Tecnológica Celso Suckow da Fonseca (CEFET-RJ), do Centro Federal de Educação Tecnológica de Minas Gerais (CEFET-MG) e das escolas técnicas vinculadas às universidades federais.

O posicionamento dos atores sociais sobre a ênfase na expansão por meio de vagas públicas, como era de se esperar, foi polarizado, entre aqueles contrários à iniciativa governamental, como a ABMES, por considerar que os gastos públicos serão excessivos, e aqueles que apoiaram o programa e suas repercussões em prol da redução das desigualdades regionais e incremento de vagas noturnas, como a UNE e a ANDIFES. A entidade representativa dos dirigentes universitários foi a principal interlocutora do governo federal, tanto durante a elaboração do programa como na interface com suas associadas. Não apenas todas as IFES aderiram ao REUNI, em 2007, como seus reitores subscreveram o documento intitulado "Manifesto da Universidade Nova”, em dezembro de 2006, no qual defendiam a essência do que se tornaria o programa governamental.

Já o ANDES-SN defendeu que o caminho para ampliar as vagas na educação superior de modo que universalizasse a oferta seria a progressiva estatização das instituições privadas. Segundo o sindicato, o acréscimo na relação professor-aluno desconsiderou que professor não apenas atende à graduação, mas à pós-graduação, à pesquisa, executa tarefas administrativas e supervisiona atividades de extensão. A meta de 90\% de aprovação é considerada demasiado elevada, o que sugere para o sindicato docente que as IFES teriam de adotar um sistema de aprovação em massa. No entendimento do ANDES-SN, os resultados do programa serão a precarização do trabalho docente, a precarização dos processos de formação, o aumento das classes por docente e a priorização do ensino em detrimento da pesquisa e da extensão.

Os dois últimos meios pelos quais a política educacional de expansão da oferta expressava-se foram: o combate às desigualdades regionais e a expansão dos cursos noturnos. Embora ambos constassem do conteúdo retórico da plataforma eleitoral do candidato FHC, não se materializaram em quaisquer medidas concretas de ação estatal.

A expansão de instituições, cursos e vagas, tendo como objetivo a redução das desigualdades regionais, tornou-se consenso da política educacional - com exceção dos dois organismos multilaterais que não tratam do assunto - entre os atores sociais. Ainda que não tenha sido objeto de polêmica, vale lembrar que a expansão das IFES ocorreu em todas as capitais do país, enquanto o segmento privado teve crescimento

ajustado. Sobre a metodologia de cálculo, consultar as diretrizes gerais do REUNI (Brasil; REUNI, 2007). 
caótico e desenfreado sem qualquer direcionamento espacial, concentrado no eixo Sul-Sudeste, mais especificamente em São Paulo, estado mais rico da federação, com vistas a obter maior lucratividade da clientela com renda mais elevada.

A política de expansão extensiva e intensiva do segmento federal conduzida pelo Governo Lula apresentava o claro objetivo de reduzir as distâncias geográficas e as desigualdades regionais. A agenda do governo em tela, por sua vez, materializou-se em ação concreta, à medida que as universidades federais abriram novos campi no interior dos estados da Federação no âmbito dos projetos de expansão pactuados com o MEC por intermédio do REUNI. Além disso, criaram-se novas universidades federais, sendo que todas estão localizadas em cidades do interior dos estados da Federação. Ademais, o reordenamento e a expansão da rede federal tecnológica contribuiram sobremaneira para a interiorização de oportunidades educacionais.

$\mathrm{O}$ incremento de vagas no ensino noturno, sobretudo nas universidades federais, foi justificado pelo Governo FHC, no diagnóstico desenvolvido no Plano Nacional de Educação (PNE), sob o argumento estritamente econômico, como alternativa para racionalizar recursos e reduzir a capacidade ociosa e, dessa forma, promover aumento no indicador número de docentes por aluno. Vale ressaltar que não se definiu qual seria a distribuição de matrículas desejável entre os dois turnos ou nos cursos, apesar da participação esmagadora dos alunos do ensino médio em escolas públicas noturnas.

O consenso entre os atores estava na importância do ensino noturno como medida de democratização do acesso, uma vez que contemplava as necessidades dos alunos trabalhadores. Todavia, a divergência reside no tipo de instituição que deve conduzir o processo. Por um lado, ABMES e ABRUC e os organismos multilaterais BIRD e UNESCO acreditam na continuidade da expansão privada no período noturno, de preferência em cursos de curta duração para imediata entrada no mercado de trabalho. Por outro lado, a UNE, o ANDES-SN, a ANDIFES e o CRUB defendem que a saída para ampliar o ingresso da população carente dá-se pelo incremento de cursos noturnos em estabelecimentos públicos federais, nos padrões de qualidade semelhantes àqueles do período diurno.

A despeito do conteúdo retórico da plataforma eleitoral de ambos ter incluído o incremento de vagas no ensino noturno, sobretudo nas universidades federais, é possível identificar duas sensíveis diferenças entre eles no que se refere ao objetivo e ao grau de concretude da ação política. Para o Governo FHC, a justificativa tinha forte cunho econômico, como alternativa para racionalizar recursos e reduzir a capacidade ociosa, pois, segundo sua visão, a inclusão social ocorria por meio do segmento particular. Por sua vez, o Governo Lula, embora se preocupasse com a ociosidade existente no segmento federal, entendia o acréscimo de vagas no turno noturno nas IFES como medida mais adequada de acesso e de permanência no nível superior.

A gestão de FHC não logrou transformar a intenção em mudança legislativa ou implementação efetiva. Já a gestão de Lula, por um lado, fixou uma meta proporcional, ainda sem aprovação legislativa, portanto, sem eficácia legal, e, por outro, a oferta de cursos noturnos nas universidades federais tornou-se objeto de exame por parte do Poder Público. Esse instrumento de expansão passou a compor 
uma das dimensões do REUNI, em andamento no segundo mandato, com o intuito de reduzir a taxa de evasão, ocupar vagas ociosas e, ao mesmo tempo, aumentar as vagas de ingresso.

Após a análise sobre a formulação da política pública orientada para a expansão por meio do incremento na oferta, torna-se relevante abordar as iniciativas no intuito de ampliar o acesso da demanda estudantil. A ideia central consistia em instituir mecanismos que facilitassem a entrada dos estudantes em duas frentes: a) criação de formas alternativas de ingresso ao vestibular; e b) promoção de políticas afirmativas.

Havia certa concordância entre os atores que o sistema de admissão por meio dos exames vestibulares deveria ser superado. Todavia, as críticas e sugestões endereçadas a esse modelo foram muito diversas. O ANDES-SN e a UNE defendiam a extinção progressiva do vestibular e sua substituição por políticas públicas que selecionariam os estudantes nas escolas oficiais. A ABMES também se mostrou propícia à flexibilidade no acesso, na medida em que possibilitaria liberdade de escolha a suas mantenedoras para combinarem, de forma conveniente - menos dispendiosa e/ou simplificada -, mais de um formato seletivo. Já o BIRD era favorável a um sistema que combinasse a "tolerância na entrada com o rigor na saída". Em outras palavras, o banco defendia o uso de critérios flexíveis no ingresso associados à avaliação rigorosa ao longo do curso.

A LDB/1996 mencionou a necessidade de aprovação, de maneira genérica, em processos seletivos e a obrigatoriedade da conclusão no ensino médio como quesitos para a entrada em um curso de graduação. $O$ concurso vestibular continuou válido para a entrada no nível superior, ainda que não fosse requisito obrigatório para os cursos de graduação. A inovação da política pública é que esse deixou de ser o único mecanismo de entrada, possibilitando que as instituições criem processos de seleção e admissão alternativos que atendam aos interessados e suas especificidades.

Um exemplo pioneiro foi na Universidade Federal de Santa Maria (UFSM), que, em 1995, implantou o Programa de Ingresso ao Ensino Superior (PEIES) prevendo uma prova ao final de cada série do ensino médio. Outras formas de seleção foram introduzidas após a LDB, como o Programa de Avaliação Seriada (PAS), da UnB, em 1996. Parte das IES privadas passou a utilizar a avaliação de conhecimentos, cujo conteúdo ficaria a critério do curso e da instituição, enquanto outras realizam, de forma complementar entrevistas, exame curricular ou histórico escolar.

Apesar da diversidade de formas de acesso, o Exame Nacional de Ensino Médio (ENEM), instituído pela portaria n. 438/1998, passou a ser o modelo alternativo preferido pelo MEC, segundo as constantes declarações de seus dirigentes na mídia. Vale a pena enfatizar que o uso do ENEM para ingresso no nível superior foi referendado pelo posicionamento do BIRD, constante de um evento realizado em 1998, que propôs para o Brasil que o vestibular deveria ser substituído pela adoção de critérios de avaliação que levem em conta o conhecimento adquirido ao longo do ensino médio, tais como os exames finais anuais, associados à elaboração de uma prova nacional que possibilite medir o desempenho dos concluintes desse nível educacional. 
O ENEM foi elaborado inicialmente com o intuito de servir como modalidade alternativa ou complementar aos exames de acesso aos cursos de nível superior, contudo, esse exame unificado passou a ser utilizado como critério de ingresso na educação superior por um número significativo de instituições, apesar das resistências provenientes das instituições públicas, o que contribuiu para a ampliação contínua do universo de estudantes concluintes da educação básica que se submeteriam a essa avaliação. Constituído para ser um exame de saída do ensino médio, transformou-se em exame de ingresso na educação superior, assemelhando-se aos modelos do Baccalauréat francês e o Abitur alemão (Cunha, 2003).

A reação dos atores sociais às novas formas de acesso foi constituída por suas convicções e pela agenda de propostas para esse nível educacional, mas também foi embalada pelas denúncias constantes da mídia sobre o caráter excludente e elitista do exame vestibular, que reproduzia as condições prévias socioeconômicas dos estudantes. Os atores estatistas manifestaram-se sobre a permanência provisória dos exames vestibulares. A intenção era alterar os critérios de seleção e admissão de forma cautelosa. Todavia, a concordância com o MEC a respeito da substituição do vestibular não significou apoio desses atores ao ENEM. A censura ao novo exame nacional residia no provável rebaixamento das exigências de conteúdo, combinado ao caráter classificatório como medida de meritocracia demasiado insuficiente.

Por sua vez, a flexibilidade do acesso à demanda foi ao encontro dos interesses das IES particulares, pois permitiu a adoção de mais de um processo seletivo. Não é à toa que a criação do ENEM foi bem recebida pela ABMES, já que não implicava qualquer custo para a realização do processo externo de seleção. A entidade mostrou-se aliada do MEC na promoção e divulgação dos benefícios da adoção nas suas associadas.

Os novos formatos de ingresso, como alternativa completa ou parcial ao vestibular, foram postos em prática pelas IES, com o aval do MEC, durante os dois mandatos de FHC. Nesse ínterim, o ENEM assumiu o protagonismo entre os mecanismos existentes, sobretudo nos estabelecimentos privados, como instrumento mais democrático e confiável, em substituição ao tradicional exame realizado por estes. Apesar do caráter não obrigatório aos concluintes do ensino médio, a nova prova nacional consolidou-se mediante a adesão crescente das IES. O Governo Lula deu continuidade à iniciativa, por um lado, em virtude do sucesso dessa inovação institucional, uma vez que o custo político de seu abandono era demasiado elevado, por outro lado, diante da postura crítica unânime dos atores, inclusive do MEC, ao vestibular tradicional.

Esse exame nacional adquiriu centralidade na política de acesso às IES particulares no Governo Lula a partir da introdução do ProUni em 2005. Para ter acesso a bolsas de estudos, a realização da prova torna-se obrigatória, e a nota obtida tornou-se a base para a classificação e o principal critério de seleção de bolsistas pelo programa. No segundo mandato, essa forma mais democrática, ampla e imparcial de ingresso, a despeito das pertinentes críticas metodológicas dos atores estatistas, foi remodelada pelo MEC, de modo a incorporar tais advertências, com o fito de se transformar no principal formato unificado de escolha nos processos seletivos das instituições públicas federais. No início de 2010, foi criado o Sistema de Seleção 
Unificada (SISU), que é um sistema informatizado no qual as instituições públicas de ensino superior oferecem vagas para candidatos participantes do ENEM.

Enfim, o segundo mecanismo de acesso à demanda tratava das politicas afirmativas. Os atores sociais são favoráveis, bem como essas políticas estão presentes no rol de proposições dos organismos multilaterais como medida de democratização do acesso à demanda. Ainda assim, é possível vislumbrar divergências de interpretações quanto aos possíveis resultados obtidos. Apesar de defender o uso desse instrumento, o BIRD mostrou-se cauteloso em sua análise, pois, segundo ele, o impacto em termos de eficácia ainda não teria comprovação empírica e poderia haver aumento de custos que comprometeriam a eficiência, objetivos perseguidos pelo Banco Mundial. No Brasil, o debate das políticas afirmativas traduziu-se no formato de reservas de vagas por cotas raciais e/ou sociais nas IFES. Logo, os atores estatistas apresentaram visões diferentes: a UNE era favorável, sem restrições, a esse tipo de política pública, bem como à reserva de vagas a deficientes físicos nas instituições federais, enquanto a ANDIFES alertava que essa não deveria ser a única modalidade de inserção no sistema, mas deveria ser combinada com a ampliação de vagas no turno noturno.

As políticas afirmativas não apareceram na pauta dos programas de governo de FHC, bem como não foram objeto de debate durante a elaboração da LDB/1996. Apenas durante a disputa do PNE o tema veio à baila. No PNE, na seção de objetivos e de metas, havia uma preocupação, ainda que vaga, em colocar em prática políticas públicas direcionadas à população vítima de discriminação. Sob a visão do ingresso competitivo baseado em igualdade de condições, a proposta consistia em programas de compensação de deficiências formativas anteriores, cujo objetivo era equalizar as chances de entrada, acreditando-se que apenas o nivelamento acadêmico seria suficiente para a manutenção do estudante na rede educacional.

A inquietação com o tema não se traduziu em política pública, embora no apagar das luzes do segundo mandato o Poder Executivo tenha editado medida provisória convertida na lei n. 10.558/2002, dando origem ao Programa Diversidade na Universidade. Fruto do acordo de empréstimo entre o Banco Interamericano de Desenvolvimento (BID), com gerenciamento financeiro da UNESCO, o programa teve início como apoio a Projetos Inovadores de Curso (PIC) em cursinhos pré-vestibulares. A lei foi regulamentada por meio do decreto n. 4.876/2003, e o programa disseminou-se no Governo Lula, respaldado por reforma administrativa no MEC que deu origem à Secretaria de Educação Continuada, Alfabetização e Diversidade (SECAD), que constituiu a Coordenação Geral de Diversidade e Inclusão Educacional (CGDIE) para tratar das questões étnico-raciais. Percebe-se que houve preocupação em construir um aparato institucional com o intuito de contemplar um dos principais objetivos constantes do programa de governo sobre o sistema educacional, qual seja, criar novas formas de acesso à educação superior, em especial para negros e estudantes egressos da escola pública.

O Poder Executivo elaborou projeto de lei (PL) em regime de urgência com o intuito de criar um sistema especial de reserva de vagas para estudantes egressos de escolas públicas, em especial negros e indígenas, nas instituições públicas federais de educação superior. Todavia, o trâmite foi demasiado longo, sendo que o PL foi 
arquivado em 2009. O tema ainda é objeto de constante polêmica no Congresso Nacional e no meio acadêmico público. O CRUB admite a adoção dessas medidas apenas para os estudantes do ensino médio da rede pública, já a ANDIFES e a UNE são favoráveis à adoção de políticas afirmativas, apesar das ressalvas feitas quanto à necessidade de colocar em prática instrumentos complementares de facilitação no ingresso. Por sua vez, o ANDES-SN reconhece a necessidade de inclusão dos segmentos historicamente discriminados e de acesso dos mais pobres, mas adverte que se trata de medida focalizada, que encobre a ausência de universalismo da pública educacional.

A ausência de regulamentação sobre políticas afirmativas levou as instituições federais a adotarem ações próprias bastante diversificadas de inserção de alunos sob os critérios de renda ou étnico-raciais. Cabe lembrar as iniciativas pioneiras, em 2003, da Universidade do Estado do Rio de Janeiro (UERJ) e da Universidade de Brasília (UnB). No âmbito do REUNI, previa-se, de forma genérica, que as IFES adotassem ações afirmativas, sem definir qualquer parâmetro ou meta obrigatórios.

Se, por um lado, as políticas afirmativas nas federais estão a demandar por formulação, ainda que nos últimos anos as ações nesse sentido tenham se disseminado, por outro lado, estas se tornaram realidade nos estabelecimentos particulares por intermédio do ProUni. De acordo com a concepção do programa, o público alvo foi delimitado pelo critério de renda familiar per capita e as bolsas destinam-se àqueles que cursaram o ensino médio em escola pública ou como bolsistas integrais de escolas privadas, contemplando ainda os portadores de deficiência e os autodeclarados negros e indígenas.

\section{CONSIDERAÇÕES FINAIS}

O texto procurou estudar a política pública para a educação superior sob a perspectiva analítica do neoinstitucionalismo histórico. Por esse olhar, a relação entre Estado e sociedade é mediada por instituições e alicerçada na figura do Estado, ao mesmo tempo instituição e ator central da política pública. Esta é concebida pela combinação da ação estatal e das ações e reações dos demais atores mediante os elementos centrais da agenda governamental.

O fio condutor é o entendimento dos atores e das instituições políticas (polity) como essenciais para a compreensão do processo político (politics), bem como para o desenho e a conformação das políticas públicas (policies). Por essa perspectiva, a participação de grupos, de classes e do Estado no processo político e a maneira pela qual eles interpretam (ideias) e perseguem seus interesses e os resultados de seus esforços são moldados pelo arcabouço institucional, assim como a trajetória do fazer político (politics) molda e, simultaneamente, é moldada pela dimensão material da política (policy).

Procurou-se responder à indagação central do artigo a respeito da existência de continuidades e/ou descontinuidades na ação estatal durante o período estudado. Em outras palavras, a pesquisa investigou se havia traços de ruptura ou continuidade no Governo Lula, em relação a seu antecessor, no que tange à política educacional 
para o nível superior. Para isso, é importante considerar no estudo da política educacional o elemento inercial dado pela continuidade das políticas atribuído ao processo de realimentação da path dependence, da mesma forma que a existência de traços de ruptura provenientes da mudança institucional.

A agenda educacional da campanha do Governo Lula mostrava completa oposição à de seu antecessor. Entretanto, a concepção inicial foi remodelando-se na medida em que surgiram os limites dados pela pressão dos atores sociais no Congresso Nacional em reação às iniciativas governamentais. Ademais, a existência de políticas estruturadas sob um arcabouço institucional sólido impediram grandes transformações, até porque o custo do abandono das políticas consolidadas era demasiado elevado, com fortes repercussões de cunho eleitoral. Essas forças combinadas são elementos explicativos do movimento de continuidade da política pública.

A diversidade de cursos e a diferenciação institucional que foram estimuladas pelo Governo FHC, sob a aprovação do BIRD, da UNESCO e dos atores defensores dos interesses das IES privadas, foram duramente criticadas no programa de governo e na gestão Lula, contudo, permaneceram no espectro da ação estatal, a despeito das tentativas de restringir sua expansão, a exemplo dos centros universitários. Quanto à demanda, não houve resistência, pois o ENEM consagrou-se como alternativa aos exames vestibulares. Porém as políticas afirmativas que compunham a agenda herdada que foi formulada e materializada em iniciativas institucionais em alguns estabelecimentos federais sofreram resistências no Congresso Nacional e não se converteram em norma jurídica até a promulgação da lei n. 12.711/2012, que leva em consideração três critérios: os egressos do ensino médio público, a renda familiar per capita e a proporcionalidade populacional étnica/racial. $\mathrm{Na}$ linha de continuidade nas IES privadas, o ProUni traduziu os dois mecanismos: a adoção do ENEM como processo de seleção e as bolsas de estudo atreladas aos critérios de renda e étnico-racial.

Em consonância à agenda de mudanças propostas em 2002, o traço mais marcante de ruptura foi a decisão de colocar o segmento federal como protagonista do processo expansivo da educação superior. A concepção saiu do plano da retórica por meio do Programa Expansão Fase I e do REUNI, bem como pelo movimento de reorganização e expansão dos institutos federais no intuito de contemplar não só o aumento de vagas e de instituições federais para melhoria do acesso e da permanência, mas também a redução das desigualdades regionais e a ocupação de vagas ociosas nos cursos noturnos, dois outros aspectos da política de expansão que vinham sendo relegados ao segundo plano.

Conclui-se que a formulação e a implementação no Governo Lula apresentaram duplo intuito: mantiveram o crescimento absoluto do sistema educacional de nível superior, cujo predomínio esmagador concentrava-se no segmento particular, cujos elementos de continuidade são evidentes, e redirecionaram parcialmente os instrumentos existentes, em prol do segmento federal, evidenciando-se o elemento de ruptura da política pública educacional. 


\section{REFERÊNCIAS}

Associação Brasileira das Universidades Comunitárias (ABRUC).Comunitárias. Revista da ABRUC, Brasília. Disponível em: <www.abruc.org.br>. Acesso em: 3 nov. 2010. Associação Brasileira de Mantenedoras de Ensino Superior (ABMES). Considerações, recomendações e propostas do seminário "Contribuições à Definição de uma Nova Política de Ensino Superior”. Estudos, Brasília: ABMES, n. 18, jan. 1997a. Disponível em: <http://www.abmes.org.br/publicacoes/estudos/18/est18-09.htm>. Acesso em: 3 nov. 2008.

O decreto n. 2.207/97 e a LDB: avanço ou recuo? Estudos, Brasília: ABMES, n. 19, jun. 1997b. Disponível em: <http://www.abmes.org.br/publicacoes/estudos/18/ est18-09.htm>. Acesso em: 3 nov. 2008.

. Diretrizes curriculares: possibilidades de flexibilização e mudanças. Estudos, Brasília: ABMES, n. 25, 1999a.

Educação a distância: formas tradicionais e novas tecnologias. Estudos, Brasília: n. 26, nov. $1999 \mathrm{~b}$.

Programa Universidade para Todos. Cadernos ABMES, Brasília: ABMES, n. 13, 2004.

Associação Nacional dos Dirigentes das Instituições Federais de Ensino Superior (ANDIFES). Lei orgânica das universidades: proposta de um anteprojeto de lei. Educação Brasileira, Brasília: ANDIFES, n. 18 (37), p. 205-249, 2º sem. 1996.

- Reforma universitária: proposta da ANDIFES para a reestruturação da educação superior no Brasil. Brasília: ANDIFES, 2004a. Disponível em: < http://www.andifes. org.br>. Acesso em: 10 maio 2009.

. Pela expansão da educação superior, pela valorização da educação superior como bem público. Deliberação do Conselho Pleno da ANDIFES. 2004b. Brasília, 18 mar. 2004. Disponível em: <http://www.andifes.org.br>. Acesso em: 10 maio 2009.

Associação Nacional dos Docentes do Ensino Superior - Sindicato Nacional (ANDES-SN). Proposta da diretoria da ANDES - Sindicato Nacional para o Fórum. Brasília, 1989a. Mimeografado.

. Proposta do GT de politica educacional da ANDES - Sindicato Nacional para a LDB. Brasília, 1989b. Mimeografado.

. A ANDES: Sindicato Nacional e a luta pela educação pública. Universidade e Sociedade, Brasília: ANDES-SN, ano 1, n. 1, fev. 1991.

. Proposta do ANDES-SN para a universidade brasileira. Cadernos ANDES, Brasília: ANDES-SN, n. 2, p. 1-60, out. 2003.3. ed. atualizada e revisada. Disponível em: <www.andes.org.br>. Acesso: 10 mar. 2007.

. A contrarreforma da educação superior: uma análise do ANDES-SN das principais iniciativas do governo de Lula da Silva. Brasília: GTPE, ago. 2004a.

. PROUNI: um programa para subsidiar o setor empresarial. 2004b. Disponível em: <www.andes.org.br>. Acesso em: 6 out. 2009. 
Agenda para a educação superior: uma proposta do ANDES-SN para o Brasil de hoje. Texto documento aprovado no 24 Congresso do ANDES-SN. 2005. Disponível em: <http://www.anped11.uerj.br>. Acesso em: 10 maio 2009.

. Nota (preliminar) da diretoria do ANDES-SN ao Programa REUNI na Prática (O que revelam as "diretrizes" do REUNI). ANDES, 2007. Disponível em: <http://www. adufrgs.org.br/Biblioteca\%20de\%20Documentos/REUNI/Nota\%20Preliminar\%20 da\%20Andes.pdf>. Acesso em: 10 maio 2010.

Balduino, G. REUNI. 2008. Disponível em: < http://www.andifes.org.br/index. php?option=com_content\&task=view\&id=248\&Itemid=100>. Acesso em: 10 mar. 2010. Bittar, M. O ensino superior privado no Brasil e a formação do segmento das universidades comunitárias. Avaliação, Campinas: UNISO, v. 6, n. 2 (20), p. 33-42, jun. 2001.

Brasil. Decreto n. 4.876, de 12 de novembro de 2003. Dispõe sobre a análise, seleção e aprovação dos projetos inovadores de cursos, financiamento e transferência de recursos, e concessão de bolsas de manutenção e de prêmios de que trata a lei n. 10.558, de 13 de novembro de 2002, que instituiu o Programa Diversidade na Universidade. Brasília, DF, 2003. Disponível em: <http://www.planalto.gov.br/ccivil_03/decreto/2003/D4876. htm>. Acesso em: 12 ago. 2008.

Decreto n. 6.096, de 24 de abril de 2007. Institui o Programa de Apoio a Planos de Reestruturação e Expansão das Universidades Federais - REUNI. Brasília, DF, 2007. Disponível em: <http://www.planalto.gov.br/ccivil_03/_Ato2007-2010/2007/Decreto/ D6096.htm>. Acesso em: 10 set. 2008.

Lei n. 9.394, de 20 de dezembro de 1996. Estabelece as Diretrizes e Bases da Educação Nacional. Brasília, DF, 1996. Disponível em: <http://www.planalto.gov.br/ ccivil_03/Leis/L9394.htm>. Acesso em: 2 jun. 2007.

Lei n. 10.172, de 09 de janeiro de 2001. Aprova o Plano Nacional de Educação e dá outras providências. Brasília, DF, 2001. Disponível em: <http://www.planalto.gov. br/ccivil_03/leis/leis_2001/110172.htm>. Acesso em: 2 jun. 2007.

. Lei n. 10.558, de 13 de novembro de 2002. Cria o Programa Diversidade na Universidade, e dá outras providências. Brasília, DF, 2002. Disponível em: <http://www. planalto.gov.br/ccivil_03/Leis/2002/L10558.htm>. Acesso em: 13 abr. 2008.

Lei n. 11.096, de 13 de janeiro de 2005. Institui o Programa Universidade para Todos - ProUni, regula a atuação de entidades beneficentes de assistência social no ensino superior; altera a lei n. 10.891, de 9 de julho de 2004, e dá outras providências. Brasília, DF, 2005. Disponível em: <http://www.planalto.gov.br/ccivil_03/_Ato20042006/2005/Lei/L11096.htm>. Acesso em: 5 fev. 2006.

. Ministério da Educação. Programa de Apoio a Planos de Reestruturação e Expansão das Universidades Federais - REUNI. Diretrizes Gerais. Brasília, DF, 2007. Disponível em: <http://portal.mec.gov.br/sesu/arquivos/pdf/diretrizesreuni.pdf>. Acesso em: 2 fev. 2010.

Portaria MEC n. 438, de 28 de maio de 1998. Institui o Exame Nacional do Ensino Médio - ENEM - e dá outras providências. Brasília, DF, 1998. Disponível 
em: <http://www.inep.gov.br/basica/enem/legislacao/p438_280598.htm>. Acesso em: 23 jul. 2007.

Carvalho, C. H. A. A política pública para a educação superior no Brasil (1995-2008): ruptura e/ou continuidade? 2011. 465f. Tese (Doutorado em Economia) - Universidade Estadual de Campinas, Campinas, 2011.

Comunitárias exigem reconhecimento. Ensino Superior, São Paulo: SEMESP, ano 6, n. 70, jul. 2004.

Conselho de Reitores das Universidades Brasileiras (CRUB). Contribuição do Conselho de Reitores das Universidades Brasileiras ao Plano Nacional de Educação. Educação Brasileira, Brasília: CRUB, v. 21, n. 42, p. 297-304, jan./jun. 1999.

. CRUB ano 40. Uma síntese histórica. Brasília, 2006. Disponível em: $<$ http://69.59.148.5/crub/home.asp>. Acesso em: 13 nov. 2008.

Cunha, L. A. O ensino superior no octênio FHC. Educação E Sociedade, Campinas: CEDES, v. 24, n. 82, p. 37-61, abr. 2003.

Delors, J. Educação: um tesouro a descobrir. Brasília: UNESCO/Edições ASA, 1996.

Evans, P. B.; Rueschemeyer, D.; Sкорсоl, T. (Orgs.). Bringing the State back. Cambridge: Cambridge University Press, 1985.

FreY, K. Políticas públicas: um debate conceitual e reflexões referentes à prática da análise de políticas públicas no Brasil. Planejamento e Políticas Públicas (IPEA), Brasília: IPEA, n. 21, p. 211-259, jun. 2000.

Hall, P. A.; Taylor, R. C. R. As três versões do neoinstitucionalismo. Lua Nova, São Paulo: CEDEC, n. 58, p. 193-223, 2003.

Immergut, E. M. The theorical core of the new institucionalism. Politics \& Society, Londres: Sage Publications, v. 26, n. 1, p. 5-34, mar. 1998.

Lowı, T. J. Distribution, regulation, redistribution: the functions of government. In: Theodoulou, S. Z.; Cahn, M. A. (Eds.). Public policy: the essencial readings. New Jersey: Prentice Hall, 1995.

March,J. G.; Olsen, J. P. The new institucionalism: organizational factors in political life. The American Political Science Review, Washington, DC: American Political Science Association, v. 78, n. 3, p. 734-749, set. 1984.

Marques, E. C. L. Notas críticas à literatura sobre Estado, políticas estatais e atores políticos. BIB, Rio de Janeiro: ANPOCS, n. 43, p. 67-102, 1º sem. 1997.

Menicucci, T.; Maria, G. Ruptura e continuidade: a dinâmica entre processos decisórios, arranjos institucionais e contexto político - o caso da política de saúde. Belo Horizonte: Fundação João Pinheiro, n. 21, p. 2-31, nov. 2005. [Texto para discussão]

Organização das Nações Unidas para a Educação, a Ciência e a Cultura (UNESCO). Documento de política para el cambio y el desarrollo en la educación superior. Paris: UNESCO, 1995. Conferência Mundial sobre Educação Superior. Paris: UNESCO, 1998. 
Educação superior: reforma, mudança e internacionalização. In: Reunião Dos Parceiros da Educação Superior, 2., 2003, Brasília. Anais... Brasília: UNESCO Brasil, SESu, 2003.

Partido dos Trabalhadores (PT). Uma escola do tamanho do Brasil. Brasília, 2002a. Disponível em: <http://dominiopublico.qprocura.com.br/dp/22617/Uma-escolado-tamanho-do-Brasil.html?aliases=Uma-escola-do-tamanho-do-Brasil\&id=2261 > Acesso em: 3 nov. 2009.

Um Brasil para todos. Crescimento, emprego e inclusão social. Brasília, 2002b. 73p. Disponível em: <http://www.pt-pr.org.br/documentos/pt_pag/PAG\%202004/ PROGRAMAS\%20DE\%20GOVERNO/Programa\%20de\%20Governo\%202002. PDF>. Acesso em: 15 fev. 2009.

Partido da Social Democracia Brasileira (PSDB). Mãos à obra. In: Teixeira, M. (Org.). Universidade e governo: professores da UNICAMP no período FHC. São Paulo: Escuta, 2003a.

. Avança Brasil. In: Teixeira, M. (Org.). Universidade e governo: professores da UNICAMP no período FHC. São Paulo: Escuta, 2003b.

Polanyi, K. A grande transformação. As origens da nossa época. 3. ed. Rio de Janeiro: Campus, 1980. [1.ed. 1944].

Powell, W. W.; DiMaggio, P. J. (Eds.). The new institutionalism in organizational analysis. Chicago: University of Chicago Press, 1991.

Silva, P. L. B. Limites e obstáculos à reforma do Estado no Brasil: a experiência da Previdência Social na Nova República. 1992. 216f. Tese (Doutorado em Ciência Política) - Universidade de São Paulo, São Paulo, 1992.

Sкосрод, T. Bringing the State back in: strategies of analysis in current research. In: Evans, P. B.; Rueschemeyer, D.; Skocpol, T. (Orgs.). Bringing the State back in. Cambridge: Cambridge University Press, 1985.

. Protecting soldiers and mothers: the political origins of social policy in the United States. Cambridge: Harvard University Press, 1994.

TÁpIA, J. R. B. A trajetória da política de informática brasileira (1977-1991): atores, instituições e estratégias. 1993. Tese (Doutorado em Ciência Política) - Universidade de São Paulo, São Paulo, 1993.

Thelen, K.; Steinmo, S. Historical institutionalism in comparative analysis. In: Steinmo, S.; Thelen, K.; Longstreth, F. Structuring politics. Historical Institutionalism in comparative analysis. Cambridge: Cambridge University Press, 1992.

Theodoulou, S. Z. The contemporary language of public policy: a starting point. In: Hall, 1995. ; CAnn, M. A. (Eds.). Public policy: the essencial readings. New Jersey: Prentice

União Nacional dos Estudantes (UNE). A reforma universitária que a UNE quer! Proposta aprovada no 53॰ CONEG da UNE. 2004. Disponível em: <www.une.org.br>. Acesso em: 8 fev. 2007. 
.Épreciso debater a Reforma do Ensino Superior. Nota Pública. 2005a. Disponível em: <www.une.org.br>. Acesso em: 8 fev. 2007.

. Uma outra universidade é possível. Educação não é mercadoria. Manifesto em Defesa do Debate da Reforma Universitária. 2005b. Disponível em: <www.une.org.br>. Acesso em: 8 fev. 2007.

World BAnk. La enseñanza superior: las lecciones derivadas de la experiencia. Washington, DC: Banco Mundial, 1995.

O ensino superior nos países em desenvolvimento. Perigos e esperanças. Tradução de José A. Pinto Correia. Lisboa: AULP, 2000. Tradução de: Higher education in developing countries: peril and promise.

Construir sociedades de conocimiento: nuevos desafíos para la educacíon terciaria. Tradução de Roberto Pizarro. Bogotá: Quebecor World Bogotá S.A., 2003. Tradução de: Constructing kwoledge societies: new challenges for tertiary.

\section{SOBRE A AUTORA}

Cristina Helena Almeida de Carvalho é doutora em ciências econômicas pela Universidade Estadual de Campinas (UNICAMP). Professora da Universidade de Brasília (UnB).

E-mail: cristinahelenaa@yahoo.com.br 